larger the wound made in the operation the greater the surface over which infection may take place. If, however, the method here advocated is followed' $I$ do 'not believe that the last objection should be such a serious one. I have now used this method of! occluding lymphatics and veins with a view of reducing to a minimum "the subsequent dissemination in six cases.' In five of these the presence of the ligatures in no way inferfered: with the healing of the wound or gave rise to any increased pain' ; in the sixth case; however, I must admit that I thirik that they were the cause of some suppuration 'and sloughing which were noticed in the wound on the seventh day; but even here, where the operation was an extensive one, the' suppuration only lasted two days and I do not think the healing of the wound was retarded. One possible objection to their employment is that the operation is made a trifle longer.' I sometimes use as many as from 10 to 15 ligatures." From what I have seen of the after-effects of vaginal hysterectomy for carcinoma of the cervix $\mathrm{I}$ believe general dissemirution to be infinitely more rare in such cases than it is after breast operations. I cannot help thinking that the chief reason for this is that when hysterectomy is performed, prior to the actual cutting away of the uterus the broad ligaments are clamped and tied on either side, thus effectually occluding the chief lymphatics and veins coming from this organ and in this way minimising the risk of dissemination.

In conclusion I would state my belief that a "recurrent" nodule found in the neighbourhood of a scar after operation is not a very important thing in itself, but it is a most serious thing if the avenues along which it may extend have not previously been occluded, and I wonld again urge the importance of taking steps at the time of the first operation to prevent subsequent dissemination. Even if the method here suggested should not commend itself to those who may read this article I hope that the principle on which it is based may become more widely recognised and its importance more generally admitted.

Wimpole-street, $\mathrm{W}$.

\section{A CASE OF LEAD-POISONING CAUSING INSANITY.}

By. W. STEWART STALKER, M.B., CH.B. GLasG. ASSISTANT MEDICAL OFFICER, SURREY COUNTY LUNATIC ASYLUM, BROOK WOOD, WOKING.

SIR W. Gowers's address on the Metallic Poisons has opened up a subject to which more attention might be paidi.e., the nervous phenomena accompanying certain toxic conditions-and in giving the following history of a case of leadpoisoning in which certain nervous'symptoms were marked it is in the hope that it may be of interest and prove a help in the diagnosis of such cases, which too often are mistaken for other conditions, The case was one of peculiar interest, because the onset of the symptoms was so sudden that the disease was at first regarded as one of the acute specific fevers and for a time remained undiagnosed.

The patient, a plumber, aged 30 years, was admitted into the Surrey County Asylum on August 17th, 1901. For the history of the case previously to admission I am indebted to the patient's wife and I cannot be certain of its complete accuracy, but it is to the effect that on April 12th, 1901, the patient returned from work feeling chilly and having "pains all over him." By night time he was delirious and a medical man was called in on the following day who regarded the case as one of influenza and treated it accordingly. As the patient got worse a few days later another medical opinion was procured and this led to the disease being certified as typhoid fever and he was removed to an isolation hospital. After three weeks of isolation it was recognised that he was not suffering from typhoid fever and he was sent home, remaining there until his admission to the asylum. From the outset the mental symptoms were marked and the certificate on which he was admitted to the asylum stated that he suffered from delusions of persecution with hallucinations of sight and hearing. During all this period he had been wasting in a marked degree, and his condition on admission to the asylum was as follows. He was suffering from acute mania, being restless, noisy, and excited, and utterly incoherent. His mental state, in fact, very much simulated alcoholic mania. He was very emaciated, certain muscles and groups, of muscles being picked out. There was marked paralysis of his extensor muscles of the forearms and wrist-drop was very pronounced. He was unable to stand, and when held in. the upright position his legs gave way under him and he tended to drop in a sitting posture. There was very evident tremor and this was most noticeable when be attempted any movement. There was no very marked increase in the knee-jerks and ankle clonus was absent. Anæmia was very pronounced and the face was wrinkled. On the gums there was an exceedingly well-defined blue line. The pulse was very slow and the arteries were rigid. $\mathrm{No}$ examination of the eyes could be made at this time as: the patient was so restless, but later it was ascertained that there was a certain amount of optic atrophy.

Treatment was at once commenced, large doses of the bromide and iodide of potassium being given. As he refused everything in the way of food and drugs he had to be fed, and after a certain time there was evidence of gastric irritation, and raw beef-extract in small quantities was given every hour instead of the larger quantity of milk and beef-tea with which he was fed less frequently. The immediate result of the bromide was a slight abatement in the delirium, but the sleel lessness continued and the patient was getting much weaker. On the $23 \mathrm{rd}-$ that is, six days after admission--stimulants were resorted to as there were symptoms of collapse and the bromide was discontinued, On the morning of the 25 th the patient was nearly comatose and I was just on the point of giving him some strychrine hypodermically when. to my surprise, he had a well-marked epileptiform seizure and throughout the course of the day he had two others. That night heslept and in the morning he was decidedly better. From this time onward improvement was uninterrupted, perhaps the most remarkable feature being the extraordinary rapidity of the improyement in his mental condition. There wereno more epileptiform seizures, and I ascertained that there was no previous history of epilepsy. He remained in the asylum until Oct. 11th, on which day he was discharged. His condition then was as follows. $\mathrm{He}$ had greatly increased in weight and the atrophic and paralytic condition in the muscles was fast disappearing and he could write fairly legibly. Mentally he was well, but there was a certain amount of deafness. The vision was somewhat impaired. There was also evidently a certain degree of cirrhotic change in the kidney, as there was an excessive amount of pale-coloured urine of a low specific gravity passed daily.

The history derived from the patient himself after his recovery did not add much to that gained from his wife. Colic had never been marked, although at various times 'previously to the onset of his illness he had had abdominal pains of the nature of cramp. He had been an abstainer and had never had syphilis. His memory was a complete blank from the time that he became ill until the day after he had the epileptic fits.

That this was a case of lead-poisoning there can be no doubt, and the only deviation from an ordinary case of lead encephalopathy with epilepsy was the suddenness and acute mcde of the onset. Had there been any history of alcoholism the symptoms would in all probability have been attributed to that habit and the real cause perhaps overlooked. That the acute onset was the manifestation of another malady and that during the course of this malady the symptoms of lead-poisoning became apparent are quite possible; but is it not reasonable to think that with such evident symptoms of lead toxæmia in the later stages of the illness the initial symptoms were the result of the lead also? Brookwood.

Informality in a Death Certificate.-In the November number of the Maryland Medical Journal it is stated that not long ago, while the United States ship of war Chicago was lying off Netley, near Southampton, England, a sailor died from an accident and a funeral at Southampton Cemetery was planned with full naval bonours. The registrar, however, refused to issue a permit on the American surgeon's death certificate on the ground that the latter, not being a registered medical practitioner, was not qualified to certify the death. Application was then made to the coroner, who could not hold an inquest unless the body was landed. The funeral on shore had to be abandoned and the body was a few hours later committed to the sea beyond the three-mile limit. 


\section{Climital âdotes:}

\section{MEDICAL, SURGICAL, OBSTETRICAL, AND THERAPEUTICAL.}

NOTES ON A CASE OF LARYNGEAL GROWTH WITH THYROTOMY

BY W. H. Kelson, M. D. Lond., F.R.C.S. ENG., ASSISTANT SURGEON TO THE IONDON THROAT HOSPITAL.

THE following case seems to be of interest from the fact of its long duration.

A man, aged 49 years, came to the London Throat Hospital in August, 1901, complaining of difficulty in breathing and loss of voice. He stated that as a lad he was husky, but he quite lost his voice about 1869, when he went to Goldensquare Throat Hospital and became a patient there under the care of the late Sir Morell Mackenzie. Small portions of growth were at this time repeatedly removed from the left cord. This continued for about a year, when his voice being a little improved and feeling somewhat tired he suddenly ceased to attend and avoided all active laryngeal treatment for 31 years. During this period he had always had great huskiness and more or less difficulty in breathing. He said that during the last few months he had lost about two stones in weight and his breathing had become much worse. He was a spare man of somewhat cyanotic appearance; his voice was a hoarse whisper and there was strider directly he exerted himself. There was no history of syphilis in himself or tubercle or malignant disease in the family. On examination of the larynx the left arytenoid was seen to be motionless and the upper orifice of the larynx was almost blocked by a warty growth. The left vocal cord could not be seen the right was normal. The exact point of origin of the growth from the left side could not be determined; it felt hard to the finger and forceps. No ulceration could be seen and what little discharge there was contained no tubercle bacilli. Considering the rapid loss in weight and increase in symptoms the last few months the question arose as to whether malignant disease was now present. Mr. E. B. Waggett, who kindly saw the case, thought that it was a simple tumour of some kind and the pathological report on a piece removed was, "A papillary growth probably not malignant." A week after admission to hospital the patient's breathing one afternoon became very much worse, and as asphyxia appeared imminent I had to perform tracheotomy rapidly. A few days after this I introduced a Hahn's cannula and, assisted by Mr. Waggett, performed the operation of laryngo-fissure, when the growth was seen to be a large single papilloma (of the size of nalf a walnut and weighing 30 grains) arising from the left cord; there was not the slightest sign of infiltration. The growth was removed and the larynx was closed. The patieut has now a very fair voice and has resumed his occupation as cabman. The question of recurrence is of course as yet in abeyance.

old Burlington-street, $W$.

\section{TREATMENT OF WHOOPING-COUGH BY NASAL IRRIGATION.}

By Edward Magennis, M.D. R.U.I., D.P.H. R.C.S.I.

FormerLy the treatment of whooping cough was most unsatisfactory, but now I think it may be hoped that a method has been found of combating and conquering this serious and distressing disease. I have for a long time been of opinion that the origin of this complaint was located in the Schneiderian membrane and this belief has been strengthened by the report of a case published by Dr. E. M. Parne in a medical journal some weeks ago. Acting on this hypothesis I have recently treated two cases, a girl, aged two years and three months, and her brother, aged 10 months, by irrigation of the nares with warm carbolic lotion. There can be little doubt that the diseas is produced by a specific organism, as Afanassjew discovered large numbers of bacilli in the sputum in this disease, and
Hewlett in his Manual of Bacteriolugy says: "Koplik, by sowing the pellets on solidified hydrocele fluid, obtained a pure culture of a small and delicate bacillus measuring 0.8 to $1.7 \mu$ in length." The bacilli being found in the sputum could be accounted for by the escape of mucus by the posterior nares or by the extension of the disease from the Schneiderian membrane to the pharyngeal or laryngeal membranes. The strength of the lotion which I used was 1 in 40 with a little glycerine added. I procured a two-ounce syringe with an indiarubber nozzle, so that when it was in the nares it could not do any harm, no matter how the child struggled. Three syringefuls were injected into each nostril three times a day. I had only once to show the mother how to use the syringe and afterwards she and the nurse had very little trouble in using it. It is a good plan to bind down the arms with a towel or binder before using the syringe. The result of detailed daily notes of the paroxysms and amount of cough tended to prove in both cases that treatment directed to the Schneiderian membrane by thorough irrigation diminished the frequency of the paroxysms and cough and greatly reduced the duration of the disease. Of course, in this mode of treatment there is a risk of some of the fluid getting into the Eustachian tube. Dublin.

\section{9. ittirror}

or

\section{HOSPITAL PRACTICE,}

\section{- BRITISH AND FOREIGN.}

Nulla autem est alia pro certo noscendi via, nisi quamplurimas et morborum et dissectionum historias, tum aliorum tum propria collectas habere, et inter se comparare.-MORGAGNI De Sed. et Caus. Morb., lib. iv., Procmium.

\section{WEST LONDON HOSPITAL.}

\section{a CASE OF TETANUS NEONATORUM.}

(Under the care of Mr. W. MCADAM Eccles.)

AT present it cannot be doubted that practically all cases of tetanus neonatorum are the result of infection with the tetanus bacillus, and this is especially true if the disease is epidemic ; but it is possible that some of the cases which have been thus named are examples of convulsions the result of cerebral injury at birth ; at least, this has been the opinion of careful observers, such as Marion Sims, and certainly in some cases injury at the base of the brain can be found. However this may be, the vast majority of the cases are examples of true tetanus. The case recorded below is of great interest in that the antitoxin was employed and the successful resulti is noteworthy. For the notes of the case we are indebted to Dr. J. John Abramston.

An infant, aged 14 days, was admitted to the West London Hospital on July 29th, 1901, under the care of Mr. McAdam Eccles. The mother stated that up to the previous Tuesday (July 23rd) the child was breast-fed; after that he refused the breast and took food by teaspoonfuls. He passed urine freely the first week after birth, but since then he had done so with difficulty. His bowels had been confined for two days previously to admission. $\mathrm{He}$ was brought to the hospital because the mother found suddenly that she could not get the child's mouth open to feed him, and that he was seized by "fits" every time he was touched.

After admission the child was found to have a fit eight times within an hour. Between the fits the abdomen was very rigid, as were also the muscles at the back of the neck and the muscles of expression. 'The legs and arms were not so much involved but were more rigid than normal. The pulse was 120 and the respirations were 90 . The temperature on admission was $98^{\circ} \mathrm{F}$. Each fit started with a cry, the abdomen became as hard as a board, the legs and arms were drawn up into the fotal position, and the hands were clenched so firmly that a finger placed in the child's palm previously to the attack was gripped so that the whole body could be lifted en masse by it. When the open palm was placed under the child's heels the body could be lifted from the bed in one piece until he stood on his head. The face and forehead were puckered into a painful grin, respiration 